\title{
ESTRATÉGIAS E AÇõES PARA A IMPLEMENTAÇÃO DO ICMS ECOLÓGICO POR MEIO DA CO-PRODUÇÃO DO BEM PÚBLICO
}

\author{
Amery Moisés Nadir Júnior ${ }^{1}$ \\ José Francisco Salm ${ }^{2}$ \\ Maria Ester Menegasso 3
}

\begin{abstract}
Resumo: O ICMS Ecológico foi instituído com o propósito de compensar os governos municipais de potenciais perdas na arrecadação tributária. Com base nessa evidência social, o artigo apresenta um conjunto de estratégias e ações para a implementação do ICMS Ecológico por meio da co-produção do bem público. As estratégias e as ações foram obtidas mediante pesquisa bibliográfica e documental, além de pesquisa de campo realizada nos estados em que está em vigor o ICMS Ecológico. Também se discute o ICMS Ecológico e a co-produção do bem público, bem como as experiências do ICMS Ecológico implementadas nos estados brasileiros. As estratégias e ações para a implementação do ICMS Ecológico, por meio da co-produção do bem público, são discutidas e listadas em um quadro síntese. Fazem-se ainda algumas considerações sobre a implementação do ICMS Ecológico e 0 uso extra-fiscal dos tributos, com o propósito de preservar o meio ambiente.
\end{abstract}

Palavras-chave: Co-Produção do bem público. ICMS Ecológico. Meio ambiente. Políticas públicas. Tributos. Unidades de conservação.

\section{INTRODUÇÃO}

A preocupação com o meio ambiente aumentou em escala de importância desde os anos sessenta do século passado, haja vista o número crescente de manifestações e protestos contra a degradação ambiental e também as leis que foram elaboradas para proteger a natureza. No entanto, ainda há muito que ser feito. No Brasil, de forma específica, em que se pesem os notáveis avanços que já foram alcançados, o cuidado com a preservação e proteção do meio ambiente ainda não foi completamente incorporado às ações do governo e da sociedade.

Para remediar esse problema e garantir algumas funções essenciais ao desenvolvimento do país, foram criadas, nas últimas décadas, inúmeras unidades de conservação (UCs). Essas unidades, entretanto, impõem restrições ao crescimento de inúmeras comunidades rurais, pois impedem que se instalem unidades industriais dentro dos limites de seu território. Uma das alternativas para dar solução a esse problema é o pagamento por serviços ambientais, que podem ser direcionados às UCs, as quais ofereçam serviços essenciais à sobrevivência da população. Assim, o Brasil, em vista dos mecanismos regulatórios, tem optado por criar e implantar mecanismos econômicos de suporte à gestão de recursos naturais. Um exemplo é o pagamento de taxas por parte dos usuários de recursos naturais e a compensação financeira para aqueles que preservam o meio ambiente.

\footnotetext{
1 UFSC, Florianópolis, SC. E-mail: anadir@sefaz.sc.gov.br

2 UFSC, Florianópolis, SC. E-mail: ifsalm@uol.com.br

3 UFSC, Florianópolis, SC. E-mail: mariaester@udesc.br
} 
A inserção de mecanismos de tributação ambiental no sistema tributário nacional vem ocorrendo seguidamente nos últimos anos. Esses mecanismos integram os instrumentos econômicos de política ambiental cuja adoção entende-se como necessária diante das limitações evidentes dos instrumentos tradicionais de comando e controle. Os instrumentos tradicionais são regras a serem cumpridas pelos integrantes da sociedade e seu descumprimento é passível de aplicação de penalidades legais. No que se refere às questões ambientais, abrangem fiscalização e punição, licenças, zoneamentos e padrões de qualidade ambiental. Os instrumentos econômicos e, mais especificamente, os mecanismos de tributação ambiental têm sido adotados em inúmeros países nas últimas décadas (ARAÚJO, 2003).

Em consonância com essa idéia, o Estado do Paraná criou o ICMS Ecológico (Lei Complementar $n^{\circ}$ 59/1991), introduzindo o critério ambiental na partição da cota de ICMS ${ }^{4}$ a que os municípios têm direito constitucionalmente. Por meio desse mecanismo, os estados fornecem compensações financeiras às municipalidades pelo custo de oportunidade gerada em função da existência de espaços especialmente protegidos em seus territórios.

Embora os instrumentos econômicos para gestão ambiental sejam conhecidos no Brasil, sua aplicação prática ainda é incipiente. Entre as razões que levam a pouca aplicação desses mecanismos, está a necessidade de negociação política entre os diversos segmentos sociais. A ausência dessa negociação, em alguns estados, fez com que a proposta do ICMS Ecológico enfrentasse sérias restrições e forte oposição política de municípios que temiam ter perdas financeiras com a adoção de critérios ambientais na distribuição do ICMS. Há necessidade, portanto, que se desenvolvam estratégias e se proponham ações para a implementação do ICMS Ecológico, por meio da coprodução, em que participem as diversas instâncias da sociedade.

Diante dessa problemática brasileira, o objetivo a que se propõe este artigo é apresentar um conjunto de estratégias e ações para a implementação do ICMS Ecológico, por meio da co-produção do bem público. Para tanto, em seguida à introdução (1), apresentam-se algumas considerações sobre o ICMS Ecológico e a co-produção do bem público (2); listam-se, então, as experiências do ICMS Ecológico implementadas nos estados brasileiros (3); a seguir, apresentam-se as estratégias e ações para a implementação do ICMS Ecológico, por meio da co-produção do bem público (4). 0 artigo se encerra com as considerações finais (5) e as referências bibliográficas.

As estratégias e ações apresentadas neste artigo decorrem de pesquisa bibliográfica e documental, além de pesquisa de campo realizada nos estados em que está em vigor o ICMS Ecológico. É importe frisar que as teorias sobre a biosfera e as demais questões sobre ecologia não são tratadas aqui, pois elas estão além do foco principal deste artigo. Da mesma forma, os problemas e as questões ecológicas da América Latina e do Brasil têm sido tratadas sobejamente na literatura que trata do assunto (PAGAZA, 2006), e, por conseguinte, elas não são discutidas neste artigo.

\section{O ICMS ECOLÓGICO E A CO-PRODUÇÃO DO BEM PÚBLICO}

O ICMS Ecológico surgiu no estado do Paraná, em 1991, a partir de uma aliança entre o poder público estadual e os municípios. A restrição de uso do território, causada pela necessidade de preservar mananciais, e os prejuízos econômicos decorrentes dessa limitação foram as principais causas para a aliança.

De fato, o principal critério de redistribuição do ICMS é o valor agregado que reflete o nível de atividade econômica do município e a conseqüente participação na arrecadação desse imposto. A

\footnotetext{
4 Imposto sobre operações relativas à circulação de mercadorias e sobre prestações de serviços de transporte interestadual, intermunicipal e de comunicação. O ICMS é de competência dos estados e do Distrito Federal e trata-se de sua principal fonte de recursos.
} 
adoção do valor agregado estimula o estabelecimento de novas atividades comerciais e industriais, ao mesmo tempo em que prejudica os municípios que impõem restrições ao uso da terra, devido à adoção de áreas protegidas (ACQUATELLA, 2001).

Nascido sob a égide da "compensação", o ICMS Ecológico evoluiu, transformando-se, ao longo do tempo, em instrumento de incentivo, direto e indireto, à conservação ambiental (LOUREIRO, 2002; TUPIASSU, 2004). O princípio fundamental que norteia o ICMS Ecológico é o protetor-recebedor, originário do princípio da precaução. Segundo Ribeiro (1998), o princípio protetor-recebedor postula que 0 agente público ou privado, que protege um bem natural em benefício da comunidade, deve receber uma compensação financeira como incentivo pelo serviço de proteção ambiental prestado. É o oposto do princípio usuário-pagador, em que o usuário de um determinado recurso da natureza deve pagar por sua utilização.

O ICMS Ecológico encontra fundamento em princípios teóricos, muitos dos quais derivados do Direito Tributário Ambiental. Ele trata do papel instrumental do tributo, em favor da proteção do meio ambiente, principalmente da utilização de mecanismos de indução negativa ou positiva sobre as atividades que devem ser incentivadas ou desestimuladas.

O ICMS Ecológico também tem respaldo na Constituição Federal. Ela determina que $75 \%$ da arrecadação do ICMS sejam destinados ao Estado para a sua manutenção e investimentos e que $25 \%$ dessa arrecadação seja distribuída aos municípios (CF, art. 158, IV). O parágrafo único do art. 158, inciso IV, estabelece que "até $25 \%$ do ICMS da parte que pertencer aos municípios será distribuído de acordo com lei estadual", ou seja, até $1 / 4$ dos $25 \%$ pode ser rateado aos municípios que investem na preservação ambiental, desde que haja legislação estadual pertinente. Assim, em caráter nitidamente extrafiscal ${ }^{5}$, diversos estados brasileiros já implantaram o ICMS Ecológico por força de lei estadual. Os municípios que investem em projetos ambientais recebem entre $0,5 \%$ e $5 \%$ da arrecadação total do ICMS a eles destinada.

Além da conservação e preservação da natureza, o ICMS Ecológico também fomenta 0 desenvolvimento de programas de educação ambiental e ações de saneamento básico, incluindo a coleta e o tratamento de resíduos economicamente viáveis. Ademais, esse mecanismo tributário pretende, além de se tornar uma compensação financeira para aqueles municípios que têm em seus territórios unidades de conservação, servir de estímulo à melhoria da qualidade de conservação das áreas de preservação já existentes e, ainda, à criação de novos espaços protegidos.

Muito embora a receita proveniente do ICMS Ecológico não possa ser vinculada a programas específicos da área ambiental, pois a Constituição Federal, em seu artigo 167, não admite a vinculação de receitas ${ }^{6}$, isso não se transforma em empecilho para que os municípios invistam em preservação ambiental. $O$ motivo dessa ação dos municípios é que eles só serão enquadrados dentro dos critérios legais estabelecidos para repasse dos recursos, a partir de programas de ações na área ambiental (PIRES, 2001).

Persiste, contudo, o desafio de tornar o ICMS Ecológico um efetivo instrumento de política pública ambiental. Para fazer frente a esse desafio, é necessário que haja transparência nos procedimentos, abolindo-se o clientelismo e implantando-se a democratização das informações. Há necessidade de participação efetiva do cidadão e dos diversos segmentos que compõem a sociedade na formulação, na implementação e na avaliação do ICMS Ecológico. Em outros termos, para que o ICMS Ecológico possa manter, ao longo do tempo, a sua atratividade como um instrumento de conservação ambiental, é preciso que sua implementação se faça com a participação da sociedade, ou seja, por meio de processos democráticos de co-produção do bem público (SKELCHER, 2006; BERRY,

\footnotetext{
5 Extrafiscalidade: consiste na utilização do tributo com função diversa da arrecadatória, ou seja, para estimular ou desestimular comportamentos sociais.

6 Exceto para destinação de recursos para manutenção e desenvolvimento do ensino e prestação de garantias às operações de crédito por antecipação de receita (CF, art. 167, inc.IV).
} 
2005; COOPER, 2005). Essa estratégia para a produção do bem público é uma concepção emergente de prestação de serviços públicos, na qual o aparato burocrático do estado, o empresariado, as organizações não-governamentais e as comunidades politicamente articuladas compartilham responsabilidades e trabalham em rede para a implantação das políticas públicas (KATHI e COOPER, 2005; ALFORD, 2002).

A co-produção do bem público é um conceito desenvolvido no final da década de setenta. Ela consiste no envolvimento de diversos segmentos da comunidade na produção dos serviços públicos. Os seus componentes principais são a descentralização, a desconcentração e a participação. Para Tombi, Salm e Menegasso (2006), ela integra as ações tradicionalmente fragmentadas em diversos campos ou setores. Na co-produção, os governos locais assumem um papel de coordenação e de liderança, mobilizando atores governamentais e não-governamentais, assim como os diversos interesses e recursos para a produção do bem público. A co-produção do bem público serve ainda para mobilizar diversas instâncias da sociedade em torno da solução de um problema de interesse público cujo enfrentamento ultrapassa a capacidade de ação isolada do estado. Portanto, a co-produção é uma concepção de prestação de serviços públicos que envolve a participação direta do cidadão, em conjunto com outros agentes públicos e privados. Para Brudney e England (1983), os benefícios gerados pela co-produção podem ser de natureza individual, de grupo e coletiva.

Na visão de Whitaker (1980), os cidadãos influenciam a execução de muitos serviços públicos por meio de sua participação direta na prestação desses serviços. Para o autor, existem três tipos de atividades na co-produção: no primeiro tipo, os cidadãos exercem influência sobre as atividades que os órgãos governamentais realizam e na maneira como elas são distribuídas entre os membros da comunidade; no segundo, os cidadãos influenciam as políticas públicas, por meio de sua cooperação ou não-cooperação, limitando, assim, os tipos de programas que os órgãos governamentais podem implementar; no terceiro, os cidadãos e agentes públicos interagem para ajustar suas expectativas em relação à prestação dos serviços públicos.

A essência da co-produção do bem público está na comunidade, segundo Denhardt e Denhardt (2003). Na proposta desses autores, a implementação do novo serviço público ${ }^{7}$ ocorre mediante a coprodução do bem público em comunidade. Nesse tipo de comunidade, cidadãos e servidores públicos possuem responsabilidades mútuas em identificar problemas e em implementar soluções. A implementação do novo serviço público, por meio da co-produção do bem público, requer um conjunto de práticas que desafiam a administração pública tradicional. Essas práticas são as seguintes: servir cidadãos, não clientes; procurar permanentemente o interesse público; valorizar a cidadania acima do empreendedorismo; pensar estrategicamente e agir democraticamente; conscientizar-se de que a transparência e a prestação de contas não são simples; prestar serviços ao cidadão, em vez de comandá-lo; valorizar as pessoas, não só a produtividade.

A co-produção justifica-se no processo de implementação do ICMS Ecológico, uma vez que os cidadãos e servidores públicos possuem responsabilidades mútuas em identificar problemas e em implementar soluções em benefício ao meio ambiente e à proteção da biosfera. Ademais, os órgãos da burocracia do estado, incluindo o empresariado, as organizações não-governamentais, a comunidade politicamente articulada e os próprios cidadãos, são partícipes privilegiados no desenvolvimento e na implementação dos instrumentos de políticas públicas relacionadas ao meio ambiente. Essa participação é fator chave para institucionalizar e legitimar a manutenção das áreas de preservação no Brasil. Aliás, as audiências públicas mostram-se como uma das formas de participação, embora não suficientes para a magna tarefa de preservação do meio ambiente (MARSCHALL, 2004; LANDO, 2003).

7 O "Novo Serviço Público" (New Public Service) é um movimento emergente na administração pública cujo foco primário na implementação das políticas públicas reside no engajamento da comunidade, dos cidadãos e dos servidores públicos, via mecanismos de co-produção do bem público. 
Da discussão sobre o ICMS Ecológico e a co-produção do bem público, extraem-se alguns princípios que, acrescidos às propostas de Modé (2003), podem orientar as estratégias e ações para a implementação do ICMS Ecológico por meio da co-produção do bem público. O quadro 1, a seguir, sintetiza esses princípios.

\begin{tabular}{|l|l|}
\hline \multicolumn{1}{|c|}{ PRINCÍPIO } & \multicolumn{1}{c|}{ COMENTÁRIO } \\
\hline Participação & $\begin{array}{l}\text { Compreende a participação em geral, principalmente na formação das decisões administrativas, a } \\
\text { participação nos recursos e julgamentos administrativos, a participação legislativa direta (por meio da } \\
\text { instituição do plebiscito ou referendo ambiental) e a participação nas ações judiciais. }\end{array}$ \\
\hline Informação & $\begin{array}{l}\text { Trata do direito de os cidadãos terem acesso às informações sobre as diversas intervenços que } \\
\text { atinjam o meio ambiente, devendo ser assegurados a todos eles os mecanismos judiciais, } \\
\text { legislativos e administrativos capazes de tornarem tal princípio efetivo. }\end{array}$ \\
\hline Cooperação & $\begin{array}{l}\text { Diz respeito à participação conjunta do poder público e da coletividade na formação de condutas } \\
\text { para a defesa e a preservação do meio ambiente. }\end{array}$ \\
\hline Precaução & $\begin{array}{l}\text { Informa a necessidade de se afastar no tempo e no espaço o perigo potencial que determinada } \\
\text { atividade possa proporcionar ao meio ambiente. }\end{array}$ \\
\hline Prevenção & $\begin{array}{l}\text { O princípio da prevenção cuida do dever jurídico de se evitar a consumação de danos ao meio } \\
\text { ambiente. }\end{array}$ \\
\hline Desenvolvimento & $\begin{array}{l}\text { O direito ao desenvolvimento sustentável deve ser exercido de modo a permitir que sejam atendidas } \\
\text { eqüitativamente às necessidades de desenvolvimento econômico, social e ambiental de gerações } \\
\text { sresentes e futuras. }\end{array}$ \\
\hline Protentável & $\begin{array}{l}\text { Aquele que protege um bem natural, em benefício da comunidade mais ampla, e deve receber uma } \\
\text { compensação financeira como incentivo do serviço de proteção realizado. }\end{array}$ \\
\hline
\end{tabular}

\section{Quadro 1: Síntese dos princípios que norteiam a proposta do ICMS Ecológico via co-produção} do bem público.

Fonte: adaptado de Modé (2003).

No tópico (3), apresentam-se as principais experiências em uso do ICMS Ecológico em estados brasileiros. Essas experiências, acrescidas aos princípios explicitados no quadro anterior, servem de base para se formular o conjunto de estratégias e ações para a implementação do ICMS Ecológico por meio da co-produção do bem público.

\section{EXPERIÊNCIAS DO ICMS ECOLÓGICO NOS ESTADOS BRASILEIROS}

As experiências com o ICMS Ecológico, pesquisadas nos diversos estados brasileiros, demonstram que se trata de uma medida positiva que está conscientizando as populações sobre a importância da conservação ambiental. Observou-se, durante os levantamentos, que a finalidade do ICMS Ecológico é estabelecida de acordo com as prioridades ambientais e até mesmo sociais de cada estado da Federação, estimulando em especial:
a) ações de saneamento básico;
b) manutenção de sistemas de disposição final de resíduos sólidos e redes de tratamento de esgotos;
c) preservação de mananciais de abastecimento público de água;
d) criação e manutenção de unidades de conservação;
e) investimentos em educação e saúde;
f) atividades agropecuárias. 
No quadro 2, relacionam-se os critérios ambientais adotados nos estados brasileiros para 0 repasse dos recursos do ICMS Ecológico, bem como seus respectivos percentuais.

\begin{tabular}{|l|c|c|}
\hline \multirow{2}{*}{ ESTADO } & \multicolumn{2}{|c|}{ CRITÉRIOS DE REPASSE } \\
\cline { 2 - 3 } & $\begin{array}{c}\text { Unidades de conservação, terras indígenas } \\
\text { e outras áreas especialmente protegidas, } \\
\text { como mananciais de abastecimento. }\end{array}$ & $\begin{array}{c}\text { Coleta e destinação final de lixo, esgoto e } \\
\text { disponibilidade de água potável. }\end{array}$ \\
\hline Paraná & $0,5 \%$ & não possui \\
\hline São Paulo & $0,5 \%$ & não possui \\
\hline Minas Gerais & $0,5 \%$ & $0,5 \%$ \\
\hline Rondônia & $5 \%$ & não possui \\
\hline Amapá & $1,40 \%$ & não possui \\
\hline Rio Grande do Sul & $7 \%$ & não possui \\
\hline Mato Grosso & $5 \%$ & $2 \%$ \\
\hline Mato Grosso do Sul & $5 \%$ & não possui \\
\hline Pernambuco & $1 \%$ & $5 \%$ \\
\hline Tocantins & $2,5 \%$ & $2,5 \%$ \\
\hline
\end{tabular}

\section{Quadro 2: Estados que possuem ICMS Ecológico e os critérios e percentuais de repasse do recurso financeiro.}

Fonte: legislações estaduais.

Como informação adicional a esse quadro 2, expõe-se que o estado do Tocantins também prevê critérios para o controle de queimadas (2\%) e conservação de solos (2\%).

Os dados levantados indicam que todos os estados ganharam com a implantação do ICMS Ecológico, exceto o Rio Grande do Sul e São Paulo, por terem adotado modelos muito tímidos. 0 Estado do Paraná obteve grande sucesso ao ampliar significativamente suas áreas de conservação, assim como Minas Gerais, por ter criado o ICMS Ecológico em uma época em que a preservação ambiental era uma prioridade do governo mineiro, diversificando e ensinando muito as demais unidades da Federação. Já o Estado de Tocantins inovou ao incluir critérios ambientais como controle de queimadas e qualidade de conservação do solo. Entre os estados que estão discutindo a implementação do ICMS Ecológico, destaca-se o estado de Goiás, por apresentar princípios e fundamentos superiores àqueles constantes da legislação de outros estados. 0 Estado do Ceará também se destaca, porque inclui no ICMS Ecológico a certificação dos municípios, além de prever o fomento aos programas ambientais em curso. A seguir, apresenta-se uma síntese dos principais resultados e características verificados nos estados que já implementaram o ICMS em seus territórios.

\begin{tabular}{|c|c|}
\hline ESTADO & PRINCIPAIS RESULTADOS E CARACTERISTICAS \\
\hline $\begin{array}{l}\text { Paraná } \\
\text { (Lei Complementar nº 59/91) }\end{array}$ & $\begin{array}{l}\text { - } \text { aumento de } 160 \% \text { das áreas de preservação no estado; } \\
\text { - } \text { democratização do debate sobre as unidades de conservação; } \\
\text { - construção dos corredores de biodiversidade; } \\
\text { - } \quad \text { aprimoramento institucional do Instituto Ambiental do Paraná; } \\
\text { - criação do gabarito vertical }{ }^{8} \text {. }\end{array}$ \\
\hline $\begin{array}{l}\text { São Paulo } \\
\text { (Lei no } 8.510 / 93 \text { ) }\end{array}$ & $\begin{array}{l}\text { - } \quad \text { prioriza o aspecto compensatório do instrumento; } \\
\text { - } \quad \text { não considera o critério qualitativo da UC no cálculo de rateio; } \\
\text { - } \quad \text { percentual destinado ao ICMS Ecológico inexpressivo (0,5\%); } \\
\text { - } \quad \text { considera apenas as áreas de preservação sob jurisdição estadual. }\end{array}$ \\
\hline
\end{tabular}

\footnotetext{
8 Trata-se de um mecanismo de cálculo utilizado para o repasse dos recursos do ICMS Ecológico, que considera, além da quantidade de UCs, qual determinado município possui a qualidade de sua conservação.
} 
Continuação

\begin{tabular}{|c|c|}
\hline $\begin{array}{l}\text { Minas Gerais } \\
\text { (Lei ํㅡ 12.040/95) }\end{array}$ & $\begin{array}{l}\text { - criação do "ICMS Marrom" referente ao saneamento ambiental; } \\
\text { - } \quad \text { introdução de novos critérios ambientais, como: educação, saúde, área cultivada; } \\
\text { número de habitantes por município, dentre outros; } \\
\text { - incremento em mais de } 200 \% \text { das receitas municipais para aquelas prefeituras que } \\
\text { investiram em preservacão ambiental. }\end{array}$ \\
\hline $\begin{array}{l}\text { Rondônia } \\
\text { (Lei no 147/96) }\end{array}$ & $\begin{array}{l}\text { - ICMS Ecológico com caráter marcadamente compensatório, mais do que em qualquer } \\
\text { outro estado; } \\
\text { - possui um dos sistemas de cálculo do critério ambiental mais simples dentre todas as } \\
\text { legislações estaduais. }\end{array}$ \\
\hline $\begin{array}{l}\text { Mato Grosso do Sul } \\
\text { (Lei no 77/94) }\end{array}$ & $\begin{array}{l}\text { - a legislação prevê que o monitoramento financeiro e a co-gestão dos projetos } \\
\text { relacionados ao ICMS Ecológico poderão ser efetuados por meio dos Conselhos } \\
\text { Municipais do Meio Ambiente; } \\
\text { - introdução dos índices de rateio, referentes ao critério ambiental, de forma gradual e } \\
\text { sucessiva, para permitir às prefeituras se adequarem ao ICMS Ecológico. }\end{array}$ \\
\hline $\begin{array}{l}\text { Pernambuco } \\
\text { (Lei no 11.899/00) }\end{array}$ & $\begin{array}{l}\text { - em virtude dos critérios ambientais de rateio do ICMS Ecológico serem abrangentes, } \\
\text { - inssou a ser chamado de ICMS Socioambiental; } \\
\text { - introdução dos índices de critério ambiental também de forma incremental. }\end{array}$ \\
\hline $\begin{array}{l}\text { Tocantins } \\
\text { (Lei no 13.023/02) }\end{array}$ & $\begin{array}{l}\text { - possui a legislação que atribui o maior repasse de ICMS por conta do critério ambiental } \\
\text { - }(13 \% \text { ao final de } 5 \text { anos); } \\
\text { inovou ao introduzir critérios ambientais, como controle de queimadas e combate a } \\
\text { incêndios. }\end{array}$ \\
\hline
\end{tabular}

Quadro 3: Síntese das principais características e resultados do ICMS Ecológico e as respectivas leis instituidoras nos estados.

Fonte: Legislações estaduais e resultado de pesquisa em documentos dos estados.

O ICMS Ecológico, de acordo com Loureiro (2002), contribuiu para a melhoria da conservação da biodiversidade no Estado do Paraná. Essa contribuição é maior quando o ICMS Ecológico é combinado com outros instrumentos de política pública ou resulta de parcerias com órgãos federados, principalmente com os próprios municípios beneficiados. Observa-se, ainda, que implementar o ICMS Ecológico, por meio de mecanismos participativos, ou seja, por meio da co-produção do bem público é uma oportunidade para que as pessoas se reeduquem para a cidadania.

\section{ESTRATÉGIAS E AÇÕES PARA A IMPLEMENTAÇÃO DO ICMS ECOLÓGICO POR MEIO DA CO-PRODUÇÃO DO BEM PÚBLICO}

Os princípios que norteiam a proposta do ICMS Ecológico e a co-produção do bem público, somados às experiências realizadas em diversos estados brasileiros, permitem que se proponha um conjunto de estratégias e ações para a implementação do ICMS Ecológico, por meio da co-produção do bem público. As estratégias e ações serão apresentadas de acordo com a instância social que participa da implementação do ICMS Ecológico, co-produzindo a preservação do meio ambiente. Um quadro, ao final deste tópico, apresenta a síntese das estratégias e ações propostas.

\subsection{O ICMS ECOLÓGICO E OS MORADORES DAS UNIDADES DE CONSERVAÇÃO - UCS}

Os moradores das unidades de conservação são partícipes ativos da formulação, da implementação e da avaliação do ICM Ecológico, fazendo-se presente durante o processo de alocação 
dos recursos, promovendo o controle social da administração local e regional e avaliando sistematicamente a relação de sua comunidade com a unidade de conservação.

\subsection{O ICMS ECOLÓGICO E A COMUNIDADE POLITICAMENTE ARTICULADA}

O ICMS Ecológico induz a participação da comunidade local articulada, exigindo que os técnicos ambientais ouçam os reclames e as experiências dos moradores das comunidades rurais, sob pena de não comprometerem o desempenho desse instrumento.

Para isso, é necessário que os agentes ambientais se capacitem para interagir com a comunidade. Ressalte-se que, dentre os principais veículos de participação popular, no que diz respeito ao ICMS Ecológico, estão os conselhos municipais de meio ambiente, os quais possibilitam a participação integrada dos vários segmentos da sociedade.

\subsection{ICMS ECOLÓGICO E SUA CONTRIBUIÇÃO PARA O FORTALECIMENTO DO PODER LOCAL}

O ICMS Ecológico tem proporcionado aos governos locais um papel de destaque na execução das políticas públicas ambientais, configurando-se um instrumento de indução municipal pela busca de soluções para os problemas relacionados ao meio ambiente, sempre em parceria com os governos estaduais, com o governo federal e com os demais atores sociais.

Algumas experiências, em curso no Brasil, com o ICMS Ecológico,mostram que as prefeituras têm participado ativamente da implementação do instrumento, organizando diagnósticos, discutindo a criação de conselhos municipais de meio ambiente, articulando com outras municipalidades 0 enfrentamento de problemas comuns, organizando debates para tratar do aprimoramento da legislação e definição do tipo de serviço público a ser criado, para dar atendimento às demandas ambientais locais dentro de um processo participativo e educativo, no qual os munícipes são os eixos centrais.

\subsection{O ICMS Ecológico e o trabalho integrado dos órgãos governamentais}

Apesar das habituais dificuldades encontradas em estabelecer parcerias com os entes governamentais, na implementação do ICMS Ecológico, esse procedimento proporciona uma oportunidade de trabalho conjunto e integrado com os demais órgãos públicos, não só do meio ambiente, mas também daqueles ligados às finanças e ao legislativo.

A sustentabilidade de populações locais ou nativas requer a interação entre as instituições locais e globais. Portanto, pode-se esperar que populações que demonstrem capacidade de interagir de forma econômica e política com as instituições apresentem também uma chance maior de continuidade cultural e ecológica, assim como de seus sistemas de troca e subsistência.

\subsection{O ICMS ECOLÓGICO E A PARTICIPAÇÃO DAS ORGANIZAÇÕES NÃO-GOVERNAMENTAIS}

A regulamentação do denominado terceiro setor possibilitou um fortalecimento da ação da sociedade civil organizada, que, por meio de inúmeras organizações estabelecidas ao redor do planeta, atua de maneira significativa na tutela do meio ambiente. $O$ envolvimento de organizações ambientalistas, de diferentes origens e segmentos da sociedade civil, na co-produção da preservação do meio ambiente é uma estratégia importante para o sucesso da implantação do ICMS Ecológico. 
Essa estratégia tem-se mostrado mais eficiente do que aquelas que privilegiam programas governamentais de cunho fragmentário.

\subsection{O ICMS ECOLÓGICO E AS UNIVERSIDADES E ESCOLAS}

O ICMS Ecológico pode contribuir para a difusão de programas de educação ambiental nas universidades e escolas, principalmente nos estados em que os critérios de rateio exigem a implantação de programas de educação ambiental. Esses programas devem seguir as seguintes orientações, para que sejam coerentes com a proposta da co-produção do bem público:
a) a educação seja uma atividade contínua, que acompanhe o cidadão em todas as fases de sua vida;
b) a educação tenha um caráter interdisciplinar, que integre o conhecimento de diferentes áreas;
c) a educação tenha um perfil pluridimensional, que integre os aspectos econômicos, políticos, culturais, sociais da questão ambiental;
d) a educação incentive a participação social, na busca pela solução dos problemas ambientais, ao mesmo tempo em que propicie a mudança de valores, atitudes e comportamentos sociais.

\subsection{O ICMS ECOLÓGICO E O EMPRESARIADO}

O empresariado é uma das instâncias sociais que participam da implementação do ICMS Ecológico, co-produzindo a preservação do meio ambiente. A participação e o envolvimento do empresariado é de capital importância para o sucesso dessa implementação. A participação da representação empresarial nos conselhos regionais e nas reuniões que tratam das questões pertinentes às unidades de conservação está diretamente ligada ao sucesso da implementação do ICMS Ecológico. Aliás, a co-produção da preservação do meio ambiente requer essa participação da representação das associações empresariais locais, para que se desenvolva a consciência ambiental. O empresariado pode investir no ecoturismo e em programas ambientais, tornando o ICMS Ecológico mais efetivo. $O$ quadro que segue apresenta a síntese das principais estratégias e ações para implementar o ICMS Ecológico como um instrumento de preservação do meio ambiente, via coprodução do bem público.

\begin{tabular}{|c|c|}
\hline ATORES SOCIAIS ENVOLVIDOS & ESTRATÉGIAS DE AÇÃO \\
\hline $\begin{array}{l}\text { 1. Moradores das unidades de } \\
\text { conservação - UCs }\end{array}$ & $\begin{array}{l}\text { - avaliar a relação de sua comunidade com a UC; } \\
\text { - cobrar atuação da administração local e regional; } \\
\text { - participar da alocação dos recursos do ICMS Ecológico. }\end{array}$ \\
\hline $\begin{array}{l}\text { 2. Comunidade politicamente } \\
\text { organizada }\end{array}$ & $\begin{array}{l}\text { - participar dos conselhos municipais de meio ambiente; } \\
\text { - articular parcerias com as mais diversas entidades, para otimizar o ICMS } \\
\text { Ecológico; } \\
\text { - participar de debates sobre o ICMS Ecológico, com vistas a sua criação ou } \\
\text { aprimoramento institucional; } \\
\text { - definir o tipo de serviço público a ser criado pelas prefeituras, para dar } \\
\text { atendimento às demandas ambientais locais; } \\
\text { - articular reuniões com outros entes municipais, para discutir problemas } \\
\text { ambientais de caráter comum. }\end{array}$ \\
\hline
\end{tabular}


Continuação

\begin{tabular}{|c|c|}
\hline 3. Prefeituras municipais & $\begin{array}{l}\text { - criar os conselhos municipais de meio ambiente; } \\
\text { - proporcionar transparência administrativa em relação à alocação dos recursos } \\
\text { recebidos do ICMS Ecológico; } \\
\text { - instituir programas de educação ambiental; } \\
\text { - incentivar a participação dos demais atores sociais na implementação do ICMS } \\
\text { Ecológico. }\end{array}$ \\
\hline 4. Órgãos ambientais estaduais & $\begin{array}{l}\text { - realizar estudos, para compreender a relação entre a comunidade e as UCs; } \\
\text { - promover a integração da administração local e federal, visando à melhoria } \\
\text { - rentínua das UCs; }\end{array}$ \\
\hline 5. Órgãos ambientais federais & $\begin{array}{l}\text { - avaliar e monitorar as UCs sob sua jurisdição; } \\
\text { - atuar em parceria com os órgãos ambientais estaduais e municipais. }\end{array}$ \\
\hline $\begin{array}{l}\text { 6. Organizações não- } \\
\text { governamentais }\end{array}$ & $\begin{array}{l}\text { - auxiliar na implementação do ICMS Ecológico e monitorar a aplicação dos } \\
\text { recursos; } \\
\text { - gerar pesquisa aplicada e investir para a melhoria contínua do instrumento. }\end{array}$ \\
\hline 7. Universidades e escolas & $\begin{array}{l}\text { - gerar pesquisa aplicada e trabalhar em conjunto com os órgãos ambientais; } \\
\text { - dar suporte à implementação da educação ambiental nos municípios. }\end{array}$ \\
\hline 8. Empresariado & $\begin{array}{l}\text { - trabalhar junto às associações empresariais locais, para o desenvolvimento da } \\
\text { consciência ambiental; } \\
\text { - investir no ecoturismo e em programas ambientais. }\end{array}$ \\
\hline
\end{tabular}

\section{Quadro 4: Estratégias e ações para uma implementação do ICMS Ecológico por meio da co- produção do bem público.}

Fonte: elaborado pelos autores.

\section{CONSIDERAÇÕES FINAIS}

As experiências avaliadas neste artigo permitem afirmar que o ICMS Ecológico é um instrumento inovador na conservação e na preservação ambiental, proporcionando o aumento da superfície de áreas protegidas e oferecendo estímulos aos investimentos voltados ao saneamento básico e à preservação dos mananciais de abastecimento público.

Cabe ressaltar a importância da inserção do critério educação ambiental nas legislações do ICMS Ecológico, pois a educação é um importante instrumento de defesa ambiental, na qual o ser humano assume a plenitude de sua dignidade e resgata a cidadania. Reconhecidamente, a ausência de conhecimento transforma povos em agentes negativos do meio ambiente e de decréscimo econômico, contribuindo para o aumento da miséria, do desemprego e da falta de qualidade de vida.

Para aperfeiçoar e legitimar o ICMS Ecológico, é necessário aprimorar os mecanismos participativos que promovem a co-produção da preservação do meio ambiente. Sem essa participação e co-produção, o ICMS Ecológico corre o risco de se transformar em um mero ressarcimento financeiro aos municípios, perdendo a sua atratividade no decorrer dos anos.

A apropriação social dos espaços protegidos pode dar legitimidade política e social às áreas de preservação ambiental. Essa apropriação deve dar-se levando em conta os objetivos de manejo das unidades de conservação.

A regulamentação das leis do ICMS Ecológico, por meio de decretos, portarias e resoluções, é mais do que um recurso de técnica legislativa, é uma oportunidade para o aprimoramento permanente desse meio para a co-produção da preservação da natureza.

Ao finalizar este artigo, é importante destacar os resultados positivos obtidos para a preservação da natureza, com a implementação do ICMS Ecológico nos estados brasileiros, pois essa 
implementação permite 0 uso extra fiscal dos tributos com o propósito de preservar o meio ambiente. Resta, ainda, promover a discussão para a adoção de propostas para a inserção do fator ambiental no rateio dos recursos do Fundo de Participação dos Estados - FPE - ou a criação do Imposto de Renda Ecológico, como um incentivo aos contribuintes que investirem em conservação do meio ambiente. Quando isso vier a acontecer, a natureza certamente se mostrará grata!

\section{REFERÊNCIAS}

ACQUATELLA, Jean. Aplicación de instrumentos económicos en la gestión ambiental en América Latina y el Caribe: desafíos y factores condicionantes. Publicación de las Naciones Unidas. Comisión Económica para América Latina - CEPAL. División de Medio Ambiente y Desarrollo. Santiago de Chile: enero de 2001. Disponível em: < http://www.eclac.cl>. Acesso em: 12.06.04.

ALFORD, John. Why do public-sector clients coproduce? Toward a contingency theory. Administration \& Society, v.34, n.1, p.32-56, mar. 2002.

ARAÚJO, Suely Mara Vaz Guimarães de. Tributação ambiental e reforma tributária. Relatório Especial. Brasília (DF), Consultoria da Legislativa da Câmara dos Deputados, agosto de 2003, p. 3.

BERRY, Jeffrey M. Nonprofits and civic engagement. Public Administration Review, v.65, n.5, p.568578, sep./oct. 2005.

BRUDNEY, Jeffrey L.; ENGLAND, Robert E. Toward a definition of the coproduction concept. Public Administration Review. v. 43, n. 1, p. 59-65, 1983.

COOPER, Terry L. Civic engagement in the twenty-first century: toward a scholarly and practical agenda. Public Administration Review, v.65, n.5, p.534-535, sep./oct. 2005.

DENHARDT, J. V. \& DENHARDT, R. B. The new public service: serving rather than steering. New York: M. E. Sharpe, 2003.

KATHI, P. C.; COOPER, T. L. Democratizing the administrative state: connecting neighborhood councils and city agencies. Public Administration Review, v.65, n.5, p.559-567, sep./oct. 2005.

LANDO, T. The public hearing process: a tool for citizen participation, or a path toward citizen alienation? National Civic Review, v.92, n.1, p.73-82, Spring 2003.

LOUREIRO, Wilson. Contribuição do ICMS Ecológico à Conservação da Biodiversidade no Estado do Paraná. Tese (Doutorado em Engenharia Florestal) - Setor de Ciências Agrárias da Universidade Federal do Paraná, Curitiba, 206 f., 2002.

MARSCHALL, Melissa J. Citizen participation and the neighborhood context: a new look at the coproduction of local public goods. Political Research Quarterly, v.57, n.2, p.231-244, Jun. 2004.

MODÉ, Fernando Magalhães. Tributação ambiental - função do tributo na proteção do meio ambiente. Curitiba: Juruá Editora, 2003.

PAGAZA, I.P. Environmental protection and public administration in Latin America. International Review of Administrative Sciences, vol. 72 , n.1, p. 143-151, 2006.

PIRES, Éderson. ICMS Ecológico. Aspectos Pontuais. Legislação Comparada, 2001. Disponível em: <http://www1.jus.com.br/doutrina/texto.asp?id=2338>. Acesso em: 23.11.01. 
RIBEIRO, Maurício Andrés. O Princípio protetor-recebedor, 1998 Disponível em: http://www.ecologizar.com.br/vale04.html. Acesso em: 10.12.03.

SKELCHER. C. Does Democracy Matter? A Transatlantic Research Design on Democratic Performance and Special Purpose Governments. Journal of Public Administration Research and Theory Advance Access, Birmingham, April, 2006.

TOMBI, W. C., SALM, J. F., MENEGASSO, M. E. Responsabilidade Social, Voluntariado e Comunidade: Estratégias Convergentes para um Ambiente de Co-Produção do Bem Público. Organizações e Sociedade, v. 13, n. 37, p. 125 - 141, abr./jun. 2006.

TUPIASSU, Lise Vieira da Costa. A tributação como instrumento de concretização do direito ao meio ambiente: 0 caso do ICMS Ecológico, 2004. Disponível em: < http://www.planetaverde.org/tese.> Acesso em: 02.07.04.

WHITAKER, G. P. Coproduction: citizen participation in service delivery. Public Administration Review. v. 40, p. 240-246, 1980.

\section{STRATEGIES AND ACTIONS TO AN IMPLEMENTATION OF ECOLOGICAL ICMS VIA CO-PRODUCTION OF THE PUBLIC GOOD}

The ICMS Ecologico was instituted with the purpose of compensating the municipal governments for the potential loses in tax collection. This article presents a set of strategies and actions to implement the ICMS Ecologico by means of the coproduction of the public good. The strategies and actions were obtained through bibliographical and documental research, and field research developed at the States in which the the ICMS Ecológico is in use. It also presents a discussion on ICMS Ecologico and the co-production of public good, as well as, it reports the experiences resulting from the implementation of ICMS Ecologico in the Brazilian States. The strategies and action used for the implementation of the ICMS Ecologico through the co-production of public good are also discussed and outlined in a chart. Some final considerations are made about the implementation of the ICMS Ecologico.

Key words: Public Administration. Co-Production. Ecological ICMS. Environment.

Data de Submissão: outubro de 2006 Data de Aceite: maio de 2007 